\title{
LX. Remarkable solar halos and mock suns seen at the observatory of Henry Lawson, Esq., F.R.S. \&c., Lansdown Crescent, Bath
}

\author{
Edward Joseph Lowe Esq. F.R.A.S.
}

To cite this article: Edward Joseph Lowe Esq. F.R.A.S. (1849) LX. Remarkable solar halos and mock suns seen at the observatory of Henry Lawson, Esq., F.R.S. \&C., Lansdown Crescent, Bath , Philosophical Magazine Series 3, 34:231, 410-412, DOI: 10.1080/14786444908646258

To link to this article: http://dx.doi.org/10.1080/14786444908646258

冓 Published online: 30 Apr 2009.

Submit your article to this journal $[\pi$

Џll Article views: 2

Q View related articles $₫$ 
This will readily be verified by multiplication, or by substitution in the formulæ of page 437 of the last volume of this Journal. So, we might have considered the conditions requisite in order that the product

$$
\left(w_{1}+i^{\prime} x_{1}+j^{\prime} y_{1}\right)\left(w_{2}+i^{\prime} x_{2}+j^{\prime} y_{2}\right)
$$

may have the same form as its factors; and the same of other forms. These concluding remarks are not offered as continuations of the general development of the tessarine theory, but as individual instances not perhaps altogether unworthy of notice.

2 Church Yard Court, Temple,

May 8, 1849.

LX. Remarkable Solar Halos and Mock Suns seen at the Observatory of Henry Lawson, Esq., F.R.S. \&., Lansdoren Crescent, Bath. By Edward Joseph Lowe, Esq., F.R.A.S.

\section{[With a Plate.]}

1849. FEBRUARY $12^{\mathrm{d}}$ and $13^{\mathrm{d}}$. From $12^{\mathrm{d}} 22^{\frac{1}{2} \mathrm{~h}}$ a halo, A, Plate I. fig. 1, was formed encircling the sun, $\mathrm{S}$, apparently in a very thin vapour, for the sky was quite blue. All the morning there had been a dense ground-fog of some extent.

$23^{\mathrm{h}} 30^{\mathrm{m}}$. The horizontal diameter of the halo $\mathrm{A} 45^{\circ}$ and its vertical diameter $47^{\circ}$. The portion of the heavens enclosed within this circle was many shades darker than that without, especially so near the circle, for it gradually became lighter near the sun. The sun was also surrounded with a burr, and had his rays carried out considerably, at times $20^{\circ}$. The inner edge of the halo was well-defined, but the outer edge very confused; the breadth about $1^{\circ}$.

$23^{\mathrm{h}} 40^{\mathrm{m}}$. Two mock suns, B and C, fig. 2, faintly visible, partaking of the same tint as the halo, viz. pale yellow, were formed in the edge of the halo A on the sun's horizontal level,

variety of forms. Thus, let $A, B, C, D$ be four points in space, then the equation

$$
\mathrm{D}-\mathrm{C}=\mathrm{B}-\mathrm{A} \quad \cdot \cdot \cdot \cdot \cdot \cdot \cdot(a)
$$

may be used to indicate either that the lines $\mathrm{DC}$ and $\mathrm{BA}$ are equal and parallel, as is done in the system of Sir W. R. Hamilton; or we may use (a.) to denote that those lines are equal and directed to some one point in space; and, in this latter system, (when the last-mentioried point is at an infinite distance,) we may be reconducted to the former one. And other systems might be devised, each geometrical system having probably a corresponding one in analysis, and vice versâ. 
Phil Maa. S. 3. Vol. XXXIV, PT I.

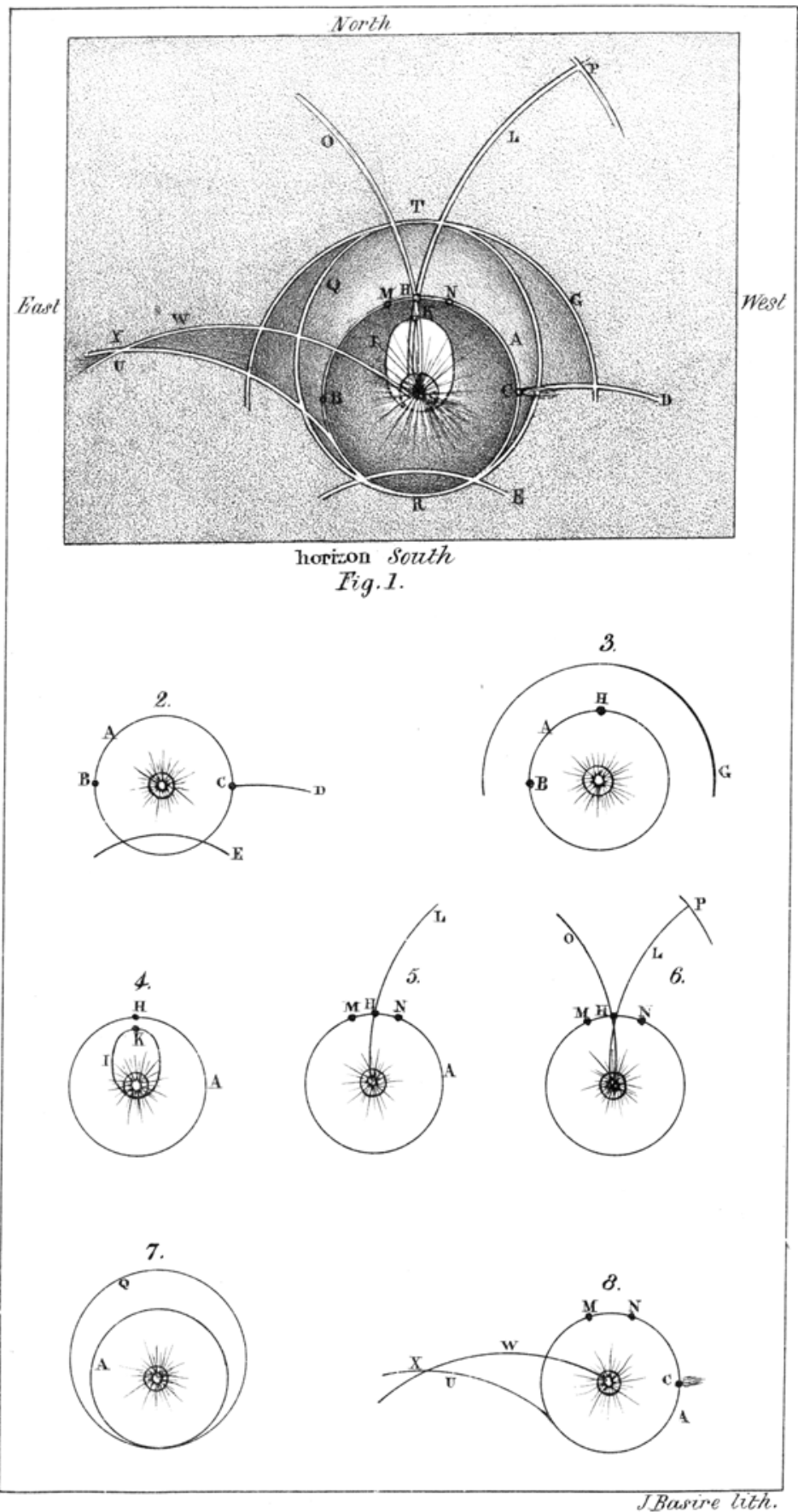


the one on the right and the other on the left side of the true sun.

$23^{\mathrm{h}} 4 \mathrm{1}^{\mathrm{m}}$. Mock sun $\mathrm{C}$ had disappeared.

$23^{\mathrm{h}} 44^{\mathrm{m}}$. Mock sun B disappeared.

$23^{\mathrm{h}} 45^{\mathrm{m}}$. From the part of the halo.A where the mock sun $C$ had appeared, there proceeded outwards an, arc of a circle, $\mathrm{D}$, which was apparently a segment of a circle whose diameter was about $90^{\circ}$. There were $30^{\circ}$ of this arc visible.

$23^{\mathrm{h}} 46^{\mathrm{m}}$. Another segment of a circle, $\mathrm{E}$, of seemingly the same diameter as $\mathrm{D}$, cut the circle $\mathrm{A}$ at $12^{\circ}$ on either side the base. $\mathrm{D}$ had disappeared.

$23^{\mathrm{h}} 55^{\mathrm{m}}$. E had vanished, and the circle $\mathrm{A}$ was indistinct; much linear cirri now appearing.

$13^{\mathrm{d}} 0^{\mathrm{h}} 10^{\mathrm{m}}$. Circle $A$ again brilliant, and the upper half of another circle, G, fig. 3, appeared, of $46^{\circ}$ radius, which had the sun for its centre; it was colourless and $1^{\circ}$ in breadth. There was about $140^{\circ}$ of this circle visible. Clouds much thinner, the sky being now clear, with the exception of a very thin uniform haze.

$0^{\mathrm{h}} 15^{\mathrm{m}}$. Mock sun $\mathrm{B}$ again just visible, and another, $\mathrm{H}$, at the apex of the circle $A$, colourless.

$0^{\mathrm{h}} 20^{\mathrm{m}}$. The phænomenon had vanished excepting the circle $A$.

$0^{\mathrm{h}} 35^{\mathrm{m}}$. A indistinct. From this time until 1 o'clock no change, the halo being feeble for a time, and then brightening up again.

$1^{\mathrm{h}}$. A curious feature now showed itself; within the circle A an ellipse, I, fig. 4, was formed, and immediately became brilliant; its horizontal diameter (measured in the centre of the ellipse) was $20^{\circ}$ and its vertical diameter $30^{\circ}$; within this ellipse the sky was much brighter than that without; its lower edge blended with the solar burr; at its apex was a mock sun, $K$, and also the mock sun $H$ again formed.

$1^{\text {h }} 5^{\mathrm{m}}$. The appearance had changed; mock sun $K$ and the ellipse I gone; but a segment of a circle, L, fig. 5, of about $140^{\circ}$ in diameter, rose from the sun $S$, and cut the circle $A$ at its summit, and extended towards the north-west; $90^{\circ}$ in length of this segment was plainly visible. Where it cut the circle $A$ at $H$ was a mock sun; also two other mock suns, $\mathrm{M}$ and $\mathrm{N}$, were formed in the circle $\mathrm{A}$ at the distance of $8^{\circ}$ on either side the vertex of this circle. All colourless. Sky becoming loaded with colourless cirri, but were less abundant near the phænomenon. Prospect, foggy ; wind, west; temperature in shade, $43^{\circ}$; Franklin's hygrometer, 95 ; barometer, $30 \cdot 15$ inches.

$1^{\mathrm{h}} 9^{\mathrm{m}}$. Another portion of a circle, $\mathrm{O}$, fig. 6 , of like dimen- 
sions with $L$, rose from the true sun, passed through the vertex of the circle $A$, where it cut the segment $L$, and stretched out towards the north-east. This was inverted with respect to L. $10^{\circ}$ of a circle of large dimensions also cut the segment $\mathbf{L}$ at $\mathbf{P}$. On the west horizon a few long muddy cirrostrati were just visible above the fog.

$1^{\mathrm{h}} 15^{\mathrm{m}}$. The circle $A$ alone remained, the other portion of the phænomenon having disappeared soon after $1^{\mathrm{h}} 10^{\mathrm{m}}$.

$1^{\mathrm{h}} 30^{\mathrm{m}}$. More clouds; the halo A fainter; but another feature was at this hour traceable-a ring, $Q$, fig. 7 , whose centre was a few degrees above the true sun, cut the circle $A$ at $\mathbf{R}$ and the circle $\mathbf{G}$ at $\mathbf{T}$; the vertical diameter was $70^{\circ}$ and the horizontal diameter $55^{\circ}$. The circle $A$ had become more elliptical; its vertical diameter was $48^{\circ}$ and its horizontal diameter $4.1_{2}^{\circ}$,

$1^{\mathrm{h}} 37^{\mathrm{m}}$. Another change took place; the circle $Q$ vanished, but there were two other segments of circles, $U$ and $W$, fig. 8, of apparently $140^{\circ}$ in diameter; these crossed each other at the point $X$, which was distant $70^{\circ}$ from the sun. 'These segments both went eastward; there were again three mock suns visible, viz. $\mathbf{M}, \mathbf{N}$ and $\mathbf{C}$; the latter was bright but colourless, and had a tail of $8^{\circ}$ in length, diminishing to a point, and proceeding diametrically opposite to the true sun.

$1^{\text {h }} 40^{\mathrm{m}}$. All had vanished but the circle $A$.

$1^{\mathrm{h}} 50^{\mathrm{m}}$. Circle A disappeared. Sky becoming clear. Temperature, $44^{\circ}$; hygrometer, 94; wind, west and calm.

$1^{\mathrm{h}} 55^{\mathrm{m}}$. Faint portion of the circle $A$ again formed above the true sun, and at this time prismatic. It finally disappeared at $2 \frac{1 \mathrm{~b}}{4}$, and the sky became thinly and partially scattered over with clouds of cirrocumuli.

The width of all the circles was $1^{\circ}$.

A fine night, succeeded by a foggy morning and slight solar halo. On the 16 th all day a prismatic solar halo, and at $3^{\mathrm{h}} 25^{\mathrm{m}}$ there were two prismatic mock suns formed on the horizontal level of the true sun in the halo of $45^{\circ}$ diameter; these lasted 7 minutes.

It is well to add, that all the measurements were made with an admirable and at the same time simple instrument invented by Mr. Lawson for this purpose. It is hung in the observatory, and is ready for use at a moment's notice.

Observatory, Lansdown Crescent, Bath, February 17 th, 1849. 